\title{
Tropical Cyclone Hazard to Mumbai in the Recent Historical Climate ${ }^{\mathscr{A}}$
}

\author{
Adam H. Sobel, Chia-Ying Lee, SuZana J. CAmargo, and Kyle T. Mandli \\ Columbia University, New York, New York \\ KERRY A. EMANUEL \\ Massachusetts Institute of Technology, Cambridge, Massachusetts
}

PARTHASARATHI MUKHOPADHYAY AND M. MAHAKUR

Indian Institute of Tropical Meteorology, Pune, Maharashtra, India

(Manuscript received 30 November 2018, in final form 17 April 2019)

\begin{abstract}
The hazard to the city of Mumbai, India, from a possible severe tropical cyclone under the recent historical climate is considered. The authors first determine, based on a review of primary sources, that the Bombay Cyclone of 1882, documented in a number of print and Internet sources and claimed to have caused 100000 or more deaths, did not occur. Two different tropical cyclone hazard models, both of which generate large numbers of synthetic cyclones using environmental data-here taken from reanalyses in the satellite era-as input, are then used to quantify the hazard, in conjunction with historical observations. Both models indicate that a severe cyclone landfall at or near Mumbai is possible, though unlikely in any given year. Return periods for wind speeds exceeding $100 \mathrm{kt}\left(1 \mathrm{kt}=0.5144 \mathrm{~m} \mathrm{~s}^{-1}\right)$ (the threshold for category 3 in the Saffir-Simpson hurricane wind scale) at Mumbai itself are estimated to be in the range of thousands to greater than 10000 years, while the return period for a storm with maximum wind speed of $100 \mathrm{kt}$ or greater passing within $150 \mathrm{~km}$ of Mumbai (possibly close enough to generate a substantial storm surge at the city) is estimated to be around 500 years. Return periods for winds exceeding $65 \mathrm{kt}$ (hurricane intensity on the Saffir-Simpson hurricane wind scale) are estimated to be around 200 years at Mumbai itself, and 50-90 years within $150 \mathrm{~km}$. Climate change is not explicitly considered in this study, but the hazard to the city is likely to be increasing because of sea level rise as well as changes in storm climatology.
\end{abstract}

\section{Introduction}

We consider the possibility of a major tropical cyclone strike on the city of Mumbai, India. By "strike" we mean either a landfall near the city, or a cyclone track that takes the center close enough to the city that the impacts are comparable to those of a landfall. The potential impact of such an event could be quite large. Mumbai is a low-lying coastal city with a very large population-over 12 million in the city itself, and over 20 million in the greater urban agglomeration - and recent floods in 2005 and 2017 (e.g., Jenamani et al. 2006; Warrier2017) have demonstrated

Supplemental information related to this paper is available at the Journals Online website: https://doi.org/10.1175/MWR-D-180419.s1.

Corresponding author: Adam H. Sobel, ahs129@columbia.edu the city's vulnerability to flooding. A cyclone, if it was to produce a large storm surge-with simultaneous high winds and possibly heavy rains as well-could be different, and perhaps even more severe than those recent events. That possibility motivates our study. We only consider the probability of a cyclone strike itself, however. The potential impacts to the city are the subjects of ongoing and possible future research.

We first argue that, despite the existence of accounts to the contrary, such an event has not occurred in the modern history of the city, at least since the start of relatively good meteorological records in the midnineteenth century. This means that historical data cannot be used on its own to construct a direct estimate of the hazard in Mumbai. It is nonetheless relevant and instructive to examine those data. We consider historical tropical cyclone track data for the Arabian Sea, including both those from the satellite era and a longer 
record (1877-present) from the India Meteorological Department, and study the distribution of tracks in space and time, with particular emphasis on the west coast of the Indian subcontinent.

We then present results from two different statisticaldynamical "downscaling" models that generate large numbers of synthetic tropical cyclones with characteristics similar to those in the observations. Because they generate synthetic datasets much larger than those available from real observations, they allow us to estimate the risks of much rarer events, including cyclone landfalls in Mumbai. The trade-off is that, precisely because the data are synthetic and lacking in adequate verification data for the rare events of interest, the potential for model error must always be considered. Comparing two different models, and considering the potential sources of model error, gives us at least some idea of the relevant scientific uncertainties. Both downscaling models take as input large-scale environmental conditions obtained from large-scale climate reanalysis datasets, and thus are consistent with the historical climate. In this study, we do not explicitly consider the effects of anthropogenic climate change. These effects may be quite important—at present, and even more so in future-but we defer consideration to future studies.

\section{Data and methods}

For an assessment of historical evidence regarding the possibility of a cyclone landfall in Mumbai on 6 June 1882 , presented in section 3 , we use publicly available texts as well as sources available in the archives of the India Meteorological Office in Pune, Maharashtra, India, as cited below. We then use observationally derived "best track" data for tropical cyclones in the Arabian Sea. We use the International Best Track Archive for Climate Stewardship (IBTrACS) data for the north Indian Ocean (Knapp et al. 2010). We use data specifically from two sources within IBTrACS: those from the Joint Typhoon Warning Center (JTWC) and those from the University Corporation for Atmospheric Research (UCAR) Global Tropical Cyclone "Best Track" Position and Intensity Data. The JTWC data cover the period from 1972 to 2016. The UCAR data extend back to 1877 , but report only intensity categories at SaffirSimpson hurricane wind scale thresholds (e.g., 64, 83, $92 \mathrm{kt} ; 1 \mathrm{kt}=0.5144 \mathrm{~m} \mathrm{~s}^{-1}$ ) as opposed to the 5-kt resolution of the JTWC data. The original source of the UCAR data is the India Meteorological Department (IMD); the characteristics of the dataset are described in greater detail by Mohapatra et al. (2012). Hoarau et al. (2012) present evidence that the intensities of some storms in the JTWC data are underestimates. We discuss the implications of this for our results below.

We show data separately for the satellite era (19792016) and the "extended" period (1877-2016) based on the JTWC and IMD/UCAR datasets within IBTrACS. Only data for the period since 1990 are officially sanctioned by the World Meteorological Organization, but for the purpose of understanding the hazard to Mumbai we view it as relevant to consider the longer periods. We assume that, in particular, a major cyclone landfall in Mumbai could not fail to have been observed in the period after 1877, so that at least for this purpose the data should be adequate. Comparing the longer and shorter periods gives some idea of the robustness of the climatology to both sampling and historical data uncertainties.

To assess the risk of events outside the range observed in the historical record, we use two statistical-dynamical downscaling models. Both models take large-scale climate data as input, and generate synthetic TCs whose origins, tracks, and intensities are dependent on those environmental data.

The first model, denoted here the "MIT model," is the one developed by Emanuel (2006) and Emanuel et al. (2008), and used in many subsequent studies of TCs and their responses to climate change (e.g., Lin et al. 2010, 2012). The technique begins by randomly seeding with weak TC-like disturbances the large-scale, time-evolving state given by global reanalysis data. These seed disturbances are assumed to move with the large-scale flow in which they are embedded, plus a westward and poleward component owing to planetary curvature and rotation. Their intensities are calculated using a simple, circularly symmetric hurricane model coupled to a very simple upper-ocean model to account for the effects of upper-ocean mixing of cold water to the surface. The seed disturbances' initial intensities are drawn from a lognormal distribution with a median intensity of about $14 \mathrm{kt}$ and with the distribution truncated to exclude intensities greater than $18 \mathrm{kt}$ and less than $9 \mathrm{kt}$. Any disturbance that has an intensity less than $14 \mathrm{kt}$ after 2 days, or which does not exceed $40 \mathrm{kt}$ at any time during its lifetime, is discarded. Applied to the synthetically generated tracks, this model predicts that a large majority of seed storms dissipate owing to unfavorable environments. Only the "fittest" storms survive; thus, the technique relies on a kind of natural selection. For the experiments performed here, the survival rate is approximately $0.01 \%$. The model is extremely fast and many thousands or tens of thousands of storms can easily be simulated. Extensive comparisons to historical events by Emanuel et al. (2008) and subsequent papers (e.g., Daloz et al. 2015) provide confidence that 
the statistical properties of the simulated events are consistent with those of historical tropical cyclones. The technique requires a calibration constant that determines the overall frequency; in this case, that constant was determined to match the observed frequency of all tropical cyclones over the Arabian Sea during the period 1980 2015. In postprocessing, storms whose lifetime maximum intensities are weaker than $40 \mathrm{kt}$ were removed.

The second model, the Columbia TC Hazard Model (CHAZ) was recently developed at Columbia University and presented by Lee et al. (2018). CHAZ also initializes weak vortices randomly, but derives its global formation rate and the local probabilities at each location from a version of the TC genesis index (TCGI,; Tippett et al. 2011). Several versions of the genesis index have been developed (Camargo et al. 2014), using slightly different predictors. Here we use the original Tippett el al. (2011) version of the genesis index, which uses as predictors absolute vorticity at $850 \mathrm{hPa}, 850-200-\mathrm{hPa}$ vertical wind shear, relative sea surface temperature, and column relative humidity. Similar to the MIT model, a beta and advection model moves the synthetic TCs. Then a stochastic, multiple linear regression model informed by large-scale environmental conditions (Lee et al. 2015, 2016) is used to calculate each storm's intensity evolution.

For this study, the MIT model was used to generate 3939 years of tracks over the Arabian Sea using environmental conditions from 1979 to 2015 derived from the National Centers for Environmental PredictionNational Center for Atmospheric Research (NCEPNCAR) reanalysis (Kalnay et al. 1996). The CHAZ model was used to generate 3840 years of tracks using environmental conditions from 1981 to 2012 derived from the ERA-Interim reanalysis (Dee et al. 2011). The Arabian Sea TCs considered here are storms that reach at least tropical storm $(34 \mathrm{kt})$ strength and form in the Arabian Sea. In addition, both models were used to generate around 9000 years of tracks for storms that pass within $150 \mathrm{~km}$ of Mumbai. The Mumbai storms can form outside of the Arabian Sea (i.e., in the Bay of Bengal). Using the stochastic intensity model, there are 40 ensemble members of each of the synthetic tracks produced by CHAZ. Thus, when considering the intensity ensemble, CHAZ has 153600 years of data in the Arabian Sea, and 360000 years of data for Mumbai storms.

Without calibration, CHAZ has a low bias in its genesis frequency in the Arabian Sea, as well as in the frequency of storms that pass within $150 \mathrm{~km}$ of Mumbai. To remove the influence of the genesis bias, we modify the sample period based on the observed frequencies. There are 149 TCs in the Arabian Sea over the observed 138-yr history, for an average of 1.08 TCs per year. One of the CHAZ intensity ensemble members, for example, has 2279 synthetic storms. We consider this to represent a period of 2110 years (2279 divided by 1.08 ) to obtain a calibrated track set. This modified period is referred to below as the "adjusted period." There is no adjusted period for the MIT model, because the model is already calibrated, as mentioned above.

The CHAZ return period curves for wind speeds in Mumbai (and the $150 \mathrm{~km}$ circle around it) in section 3c, are multiplied by constants such that the frequencies of winds exceeding $34 \mathrm{kt}$ match those in the best track data. No such calibration is applied to the return period curves from the MIT model; the MIT model's return periods at $40 \mathrm{kt}$ already, after the basin-wide calibration described above, match the observations reasonably well (despite biases in the basin-wide results, as discussed further below). The shapes of the return period curves, being the key output of the models, are not adjusted in either model. This means that intensity biases in the best track data do not influence our model results unless they result in storms being omitted entirely (i.e., storms that should have been counted as exceeding $40 \mathrm{kt}$ were not counted as such). Published studies of such biases (e.g., Hoarau et al. 2012) do not suggest that this is the case, but rather focus on errors in the diagnosed intensities of stronger storms.

\section{Results}

\section{a. The 1882 Bombay Cyclone is a myth}

A number of sources, both online and in print (e.g., Wikipedia; Emanuel 2005; Longshore 2008), document a deadly cyclone landfall in Mumbai (then Bombay) on 6 June 1882. For consistency with these sources we refer to this as the "Bombay cyclone of 1882," recognizing that the name of the city has since changed to Mumbai. Most of these sources cite a death toll of 100000 people, which would have been approximately one-eighth of the population of the city at that time. Some sources (e.g., Longshore 2008) describe a storm surge of $6 \mathrm{~m}$, which - at least if it were to happen close to high tidecertainly would have been devastating to the low-lying city. If this event were to have occurred, knowledge and understanding of it would have great importance for any assessment of the city's current and future risk.

Most of the sources provide little detail or description of the 1882 event. Many of them are simply lists of the worst tropical cyclone disasters in known world history, with the Bombay cyclone of 1882 included among them. One source (Longshore 2008) provides a paragraph; this is the most extensive description of which we are aware. No text of which we are aware listing or describing the 
Bombay cyclone of 1882 cites any primary historical source. There are, however, primary historical sources available that extensively document the cyclones occurring in the Arabian Sea during this period.

The India Meteorological Department (IMD) maintains archives of cyclone tracks as well as daily weather summaries from 1877 to 1970 for both the Bay of Bengal and the Arabian Sea. Maps are available in particular for all cyclones occurring in each calendar month during the period 1877-83. The map for June (Fig. S1 in the online supplemental material) shows no cyclone originating in the Arabian Sea. The single cyclone shown whose track reached the Arabian Sea did so after traversing the subcontinent from east to west (after its origin in the Bay of Bengal and subsequent landfall in Odisha), and this cyclone did not pass close to Bombay, rather traversing to the north in Gujarat.

J. Eliot's Cyclone Memoirs (Eliot 1893) provides a brief account of all recorded cyclones over the Arabian Sea between 1648 and 1889. This report mentions a 44th storm during 27 May-2 June 1881 and subsequently a 45th storm over the Arabian Sea during 3-4 July 1883 (Fig. S2). Eliot mentions no storm over the Arabian Sea during 1882. Also available in the archive of IMD are daily weather reports prepared for Revenue and Agricultural Department during the period of interest. The relevant weather summary was written by $\mathrm{Mr}$. H. F. Blanford. Blanford's summary of the period 5-7 June 1882 (Fig. S3) mentions no storm near the Bombay coast, nor any flooding. The Bombay station's meteorological report printed in the daily weather report also shows no indication of a cyclonic storm. It does show that on 6 June 1882, Tuesday, Bombay station reported a thunderstorm (Fig. S3d). Given the reporting practices at the time, this implies that the Bombay station experienced a thunderstorm sometime between 1000 local time (LT) 5 June and 1000 LT 6 June. Blanford's weather summary for all the days during the first week of June 1882 indicated onset of southwest monsoon over Bombay region and overcast skies associated with heavy rains from many surrounding stations. The occurrence of thunderstorms over the west coast during the onset of the southwest monsoon is a common phenomenon, and could not have caused the great destruction described in accounts of the Bombay cyclone of 1882 .

While it is difficult to prove a negative, and we make no claim to exhaustiveness in our search, it appears that the Bombay cyclone of 1882 did not occur. At least, no such event happened on 6 June 1882, and it appears unlikely that it occurred on any date close to that. While it remains possible that a similar event occurred at a different time, we have uncovered no evidence of one.
Apart from meteorological archives, it is difficult to imagine that a disaster in which 100000 people were killed, in a city of Bombay's size and importance-and one that was a major center of the British empire at the time-could have gone undocumented in historical records. A cursory search, supplemented by communication with two historians with expertise in nineteenth-century India (G. Prakash 2015, and S. Amrith 2018, personal communications), reveals no such documentation of such an event. Given these considerations, it appears to us most likely that the event simply did not occur at all.

If we are correct that the Bombay cyclone of 1882 is fictional, that leaves the interesting question of where the accounts originated. The earliest accounts of which we are aware are in U.S. newspapers from the midtwentieth century (e.g., Hall 1947; Chester 1964). As with the more recent accounts, these articles do not describe the Bombay cyclone in any detail; it appears as a brief entry in a list of historical cyclones. No sources are provided. The question of how an "urban myth" of this kind could come into the existence that it did is an interesting one, but we view it as unrelated to the pragmatic question of what Mumbai's actual risk is in the present. The latter question is the focus of this paper and so we do not pursue the former question further here.

\section{b. Historical tracks}

In this section we discuss historical cyclone tracks in the Arabian Sea. As geographical context for this and subsequent sections, Fig. 1 shows a map of western India (and southern Pakistan); Mumbai's location is indicated by the red star, and Maharashtra, the state in which Mumbai is located, is labeled, as are the several surrounding states. Figure 2 shows a map of Mumbai and its surrounding regions.

Figure 3 shows observed cyclone tracks from the period 1979-2016. The climatology of TCs in the Arabian Sea during this period is described in more detail by Evan and Camargo (2011). Storms occur primarily in the pre- and postmonsoon seasons, and are absent during July-September, being suppressed by the strong vertical shear associated with the monsoon. They are infrequent, with the average annual total being around 1-2 storms per year. Most Arabian Sea storms are weak, not exceeding tropical storm intensities (35-65 kt, or $17-33 \mathrm{~m} \mathrm{~s}^{-1}$ ) but a few reach high intensities. During the period 1979-2016, the number of storms reaching maximum intensities at tropical storm and categories $1-5$ are $45,10,1,4,3$, and 1 , respectively. No intense storms made landfall close to Mumbai (indicated by the black star) during this period, though a couple of weaker ones did so to the south. Of particular interest are two storms that made 


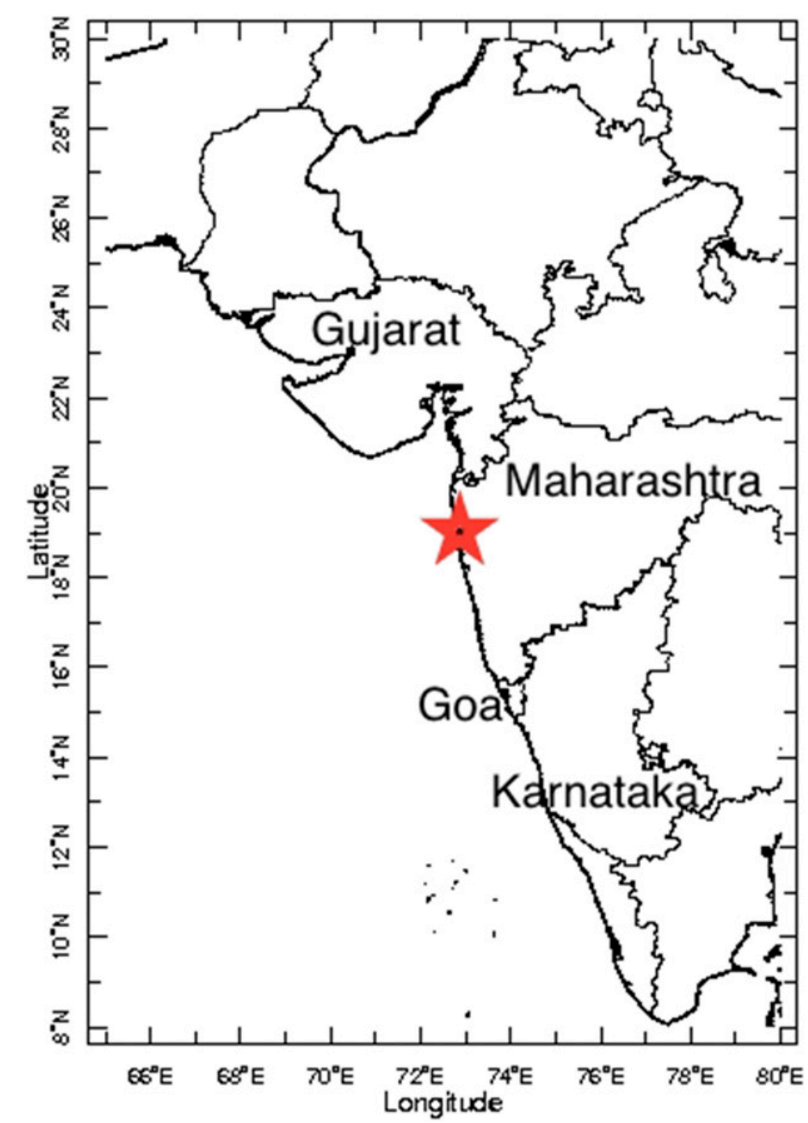

FIG. 1. Map of western India. Mumbai is marked with the star, and Maharashtra and other nearby states are labeled.

landfall in Gujarat, to the north of Mumbai, during this period. One is the 1998 Gujarat cyclone (Joint Typhoon Warning Center designation: 03A; India Meteorological Department designation: ARB 02). Both of these made landfall as storms powerful enough to generate significant storm surges. The 1998 storm is reported to have produced a surge of $4.9 \mathrm{~m}(16 \mathrm{ft})$.

Also apparent in Fig. 3 is a relative absence of tracks altogether (either low- or high-intensity storms) along and just offshore of the west coast of India south of Gujarat, including the region around Mumbai. There appears to be a preference for storms to move from south to north (or east to west) in this region, with very few storms acquiring a sufficient eastward component to their translation velocity at a location far enough south to strike Mumbai.

Figure 4 shows the tracks from the extended dataset from 1879 to 2016 . The number of tracks is naturally much larger than in Fig. 3, though the observational uncertainties are larger because of a lack of satellite observations, particularly early in the record. Toward the end of this period, just before the period shown in
Fig. 3, the so-called Porbandar cyclone of 1975 made landfall in Gujarat. Dube et al. (1985) report that this storm produced an observed storm surge of $2.7 \mathrm{~m}$ at Porbandar based on a poststorm survey, in reasonably good agreement with their simulated value of $2.2 \mathrm{~m}$ at that station, and the same simulations indicate surges as large as $4.1 \mathrm{~m}$ farther south along the coast. As in Fig. 3, a preference for landfalls in Gujarat versus farther south is apparent in Fig. 4, as is a relative dearth of tracks close to the coast to the south.

Since the total number of storms even in this extended sample is modest (131 storms before 1979), an important question is to what extent this sample would be representative of a longer time period (including possible influences from low-frequency climate variability), and just how unlikely it would be for a cyclone-particularly an intense one such as the 1975 or 1998 Gujarat stormsto turn right while moving northward and make landfall near Mumbai.

Figures $5 \mathrm{a}$ and $5 \mathrm{~b}$ show accumulated cyclone energy (ACE) densities for the satellite-era and extended besttrack data, respectively. ACE density is defined as the sum of squared maximum wind speeds over all 6-h periods when the storm is within a given grid box. The images are qualitatively similar in most respects, with the highest values in the northeast Arabian Sea south of Gujarat. The region of low values offshore of Mumbai is less apparent in the extended dataset than it is in the satellite era, however, suggesting that perhaps the satellite era is not representative of the true long-term climatology in this respect. The satellite era data also show greater values of ACE farther offshore, raising the possibility that some storms that did not make landfall (or did not do so in or near India) might have been missed in the earlier record.

\section{c. Synthetic tracks}

In this section we show synthetic tracks from CHAZ and the MIT model. Figure 6 shows ACE densities; these can be compared with the observed plots in Fig. 5. In both models, the values of ACE are lower and the patterns are smoother (Figs. 4a,c) than those in observations (Fig. 3). In CHAZ, the low bias is partially due to the biases in the formation rate. Using the adjusted period defined in section 2, the peak values of the ACE (Fig. 4b) become larger, and closer to those in Fig. 3 as well as those in the MIT model (Fig. 4c). The smoother ACE pattern and lower values in Figs. 4b,c occur also in part because we are using tracks from periods much longer than that of the observational record. When using only 32 year of model data (not shown), the sharpness and the peak value of the simulated ACE are similar to those in Fig. 3a. 


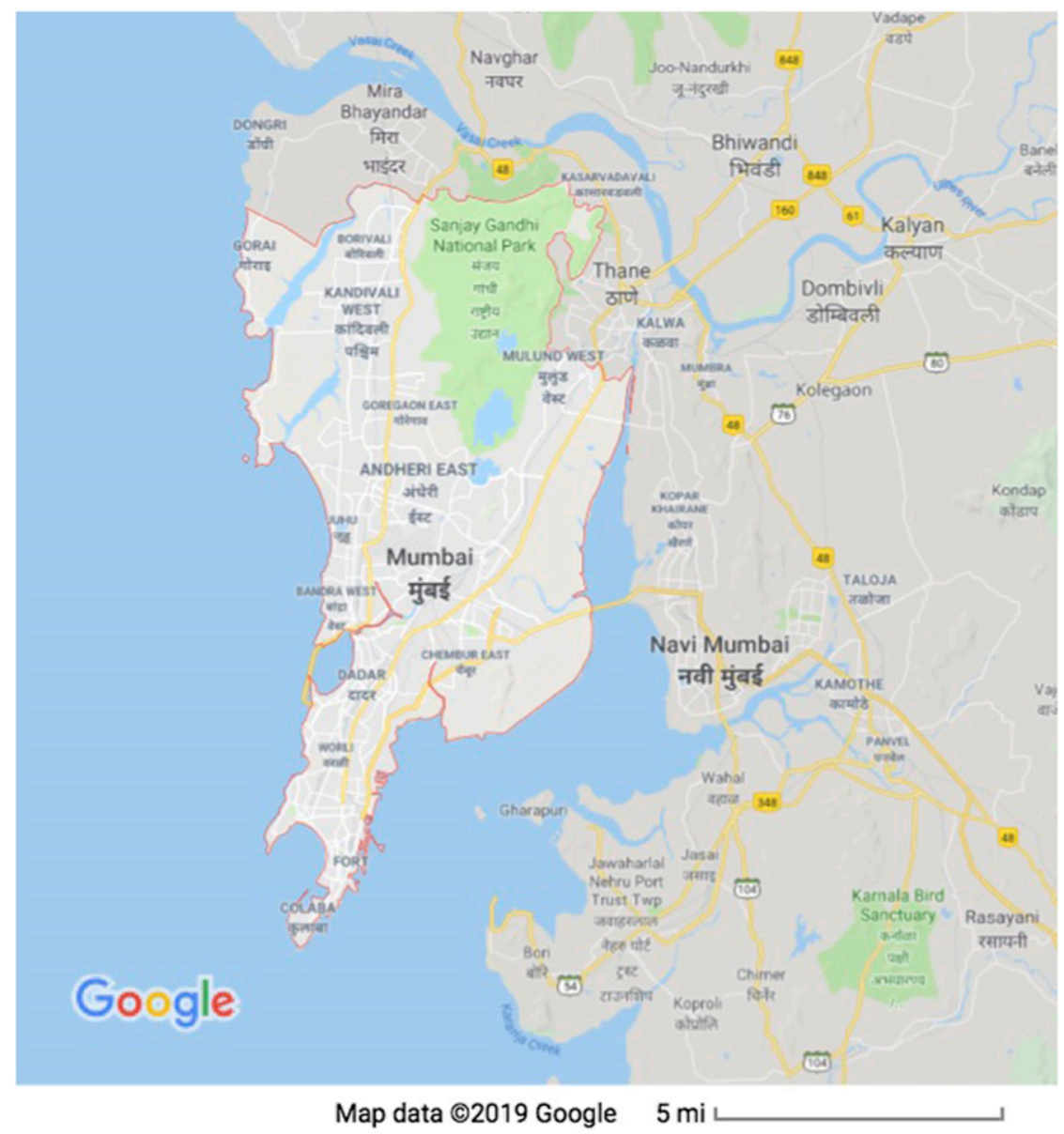

FIG. 2. Map of Mumbai and adjacent region.

For our purpose, the most important discrepancy between models and observations is the low bias in both models in the northern part of the Arabian Sea, including just offshore of Mumbai. This needs to be considered as we interpret our hazard estimates, and we do so below.

Figure 7 shows the 30 most intense synthetic storms to come within $150 \mathrm{~km}$ of Mumbai over 9000 years in both models. We see that both models produce storms that reach Mumbai's vicinity at much higher intensities than are found in the best-track data. While this could, of course, be due to model error, it is also possible (and in our view likely) that storms at these intensities are possible near Mumbai, but rare, and have not been observed only due to the shortness of the observational record. Figure 8 shows intensity versus annual exceedance frequency (Fig. 8a) and return period (Fig. 8b), respectively, from both models and observations. For the lesser intensities and shorter return periods resolved well by the observations, both models predict greater hazard (lower return periods at a fixed intensity) than observations, with the MIT model giving slightly greater hazard than CHAZ. For the longer return periods not resolved by the observations, the results from the two are similar at intensities of $100-110 \mathrm{kt}$ with return periods of

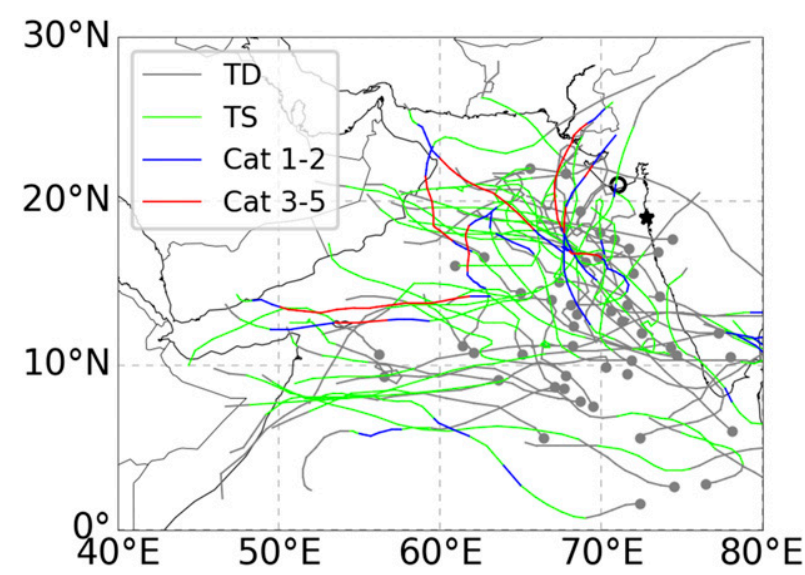

FIG. 3. Historical best tracks, 1979-2016, color coded by intensity using the U.S. Saffir-Simpson hurricane wind scale. 


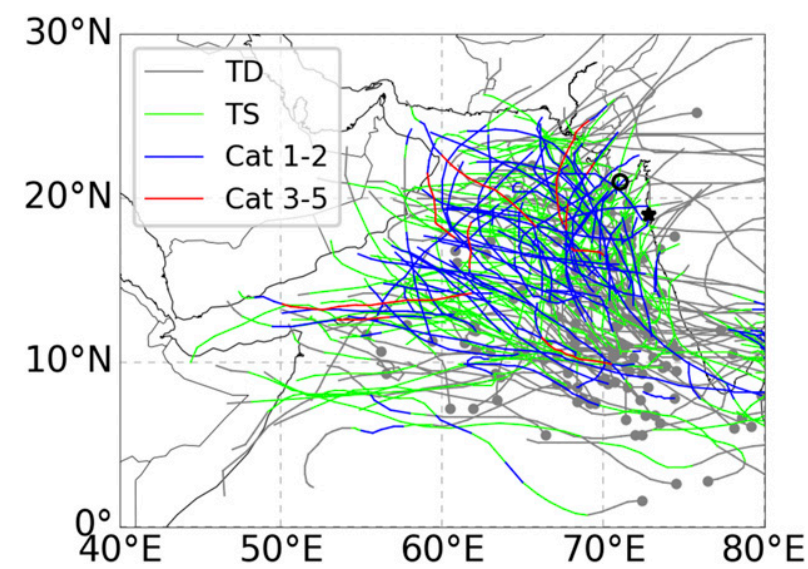

FIG. 4. Tropical cyclone tracks from the India Meteorological Department's extended dataset, 1879-2016, color coded by intensity using the U.S. Saffir-Simpson hurricane wind scale.

200-500 years. After that, the results differ, but both predict nonzero probabilities of high-intensity storms.

To estimate the return period curves for actual wind speed at Mumbai, we use a parametric wind model from Chavas et al. (2015) (CLE15). CLE15 is a theoretically based parametric wind model that takes a measure of azimuthally averaged maximum surface wind and one of several measures of storm size and structure and outputs an azimuthal mean radial profile of surface winds. We then unfold the radial mean profiles to produce twodimensional wind fields and add motion-induced asymmetries. We use the implementation of CLE15 which takes the RMW as the measure of storm size; the values chosen are described below. Other key parameters include the Coriolis parameter (here $5 \times 10^{-5} \mathrm{~s}^{-1}$ ) and ratio of the surface exchange coefficients of enthalpy and momentum (here set to an empirical function of wind speed, from CLE15), and others which are set to their default values.

CHIPS in Emanuel's model generates its own RMW through explicit internal dynamics. For observed and the synthetic CHAZ storms, we use the climatological equation for RMW from Knaff et al. [2015; see Eq. (1) therein]. This climatological equation is derived using reconnaissance data from the Atlantic and western North Pacific basins. It is a function of TC intensity and latitude. Using independent data, Knaff et al. (2015) show that this equation explained $17 \%$ of the observed RMW variance in the western North Pacific and $33 \%$ in the Atlantic. For the 9000 years of Mumbai records, the mean RMW estimated using the Knaff et al. (2015) equation in CHAZ is $77 \mathrm{~km}$ with a standard deviation of $22 \mathrm{~km}$. RMWs in the MIT model have a mean of $97 \mathrm{~km}$ and a standard deviation of $55 \mathrm{~km}$. Both RMWs have similar dependence on latitude and intensity, increasing (a)

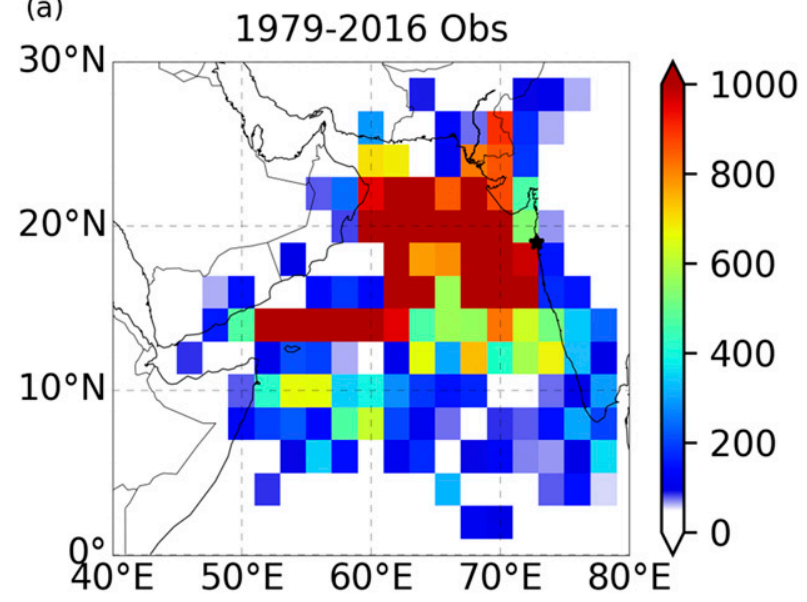

(b)

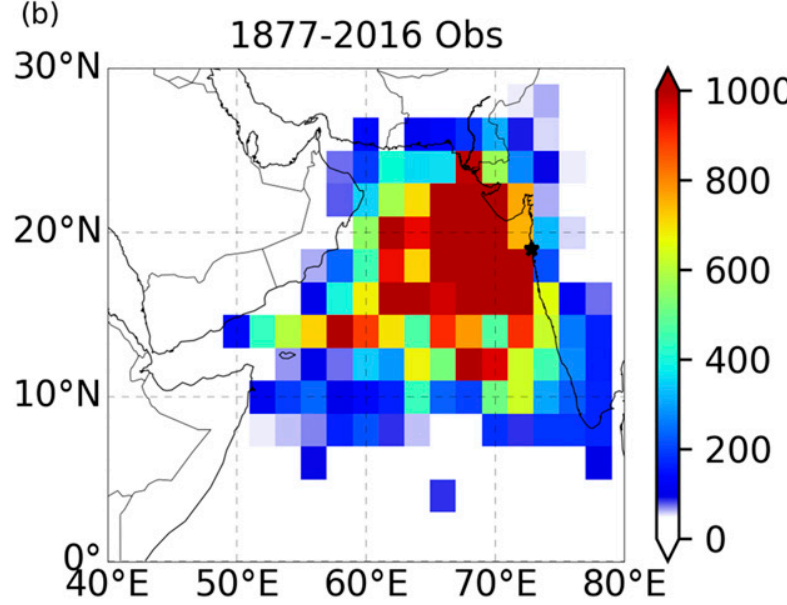

FIG. 5. Observed accumulated cyclone energy (ACE) density $\left(\mathrm{m}^{2} \mathrm{~s}^{-2} \mathrm{yr}^{-1}\right)$ for (a) 1979-2016 and (b) 1877-2016.

slightly with latitude and decreasing with storm intensity; these relationships occur by construction when using the Knaff et al. (2015) equation.

With these RMWs and CLE15, the return period curves for actual wind speed at Mumbai are calculated and shown in Fig. 8 (thick dashed line). As described in section 2, the model curves have been calibrated so that the return periods at the lowest wind speeds shown match those in the observations. In the case of CHAZ, the model curve is forced to match the observations at $35 \mathrm{kt}$, while in the MIT model only a basin-wide calibration is applied. Perhaps partly fortuitously, the MIT model's overall TC frequency, and thus its return period at $40 \mathrm{kt}$ (the lowest value shown for that model), matches the observations reasonably well at Mumbai despite the model's overall low frequency bias in the northern Arabian Sea, as seen, for example, in ACE (Figs. 5 and 6); there are sharp gradients near the coast, so that slight differences in tracks can be important. 
(a)

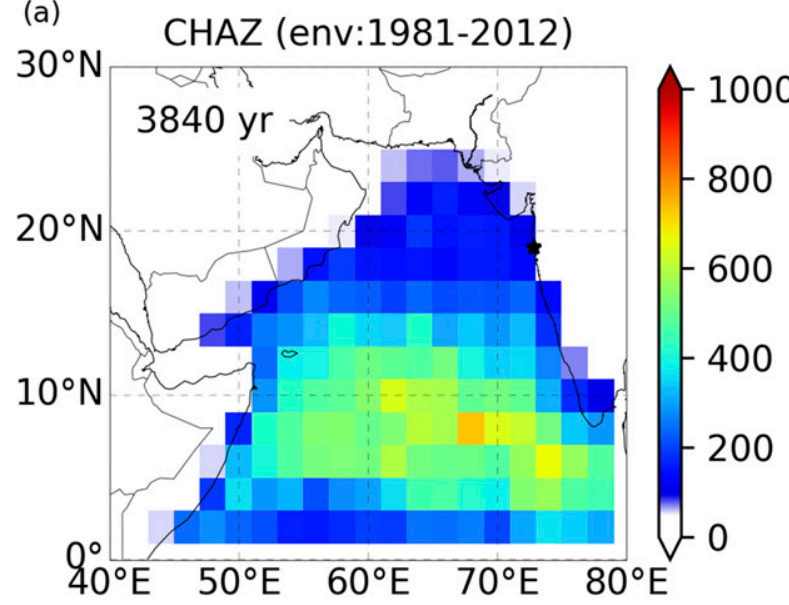

(b)

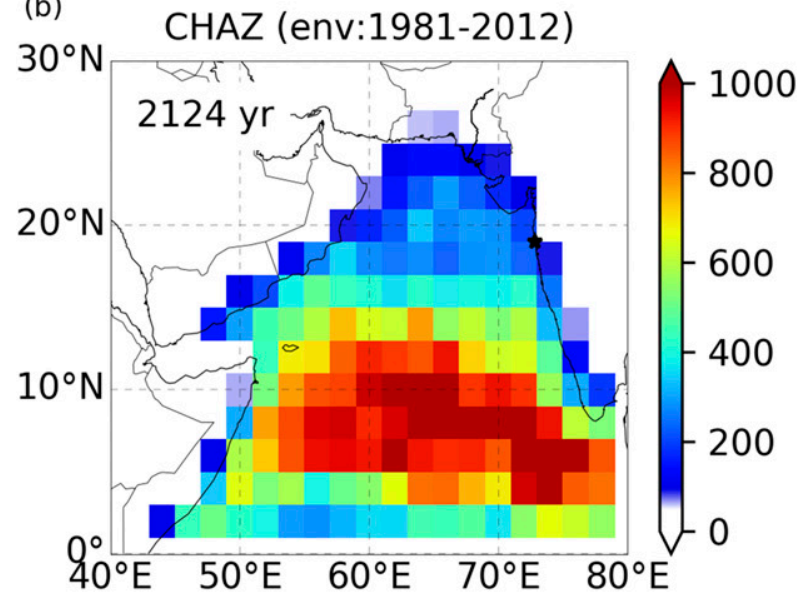

(c)

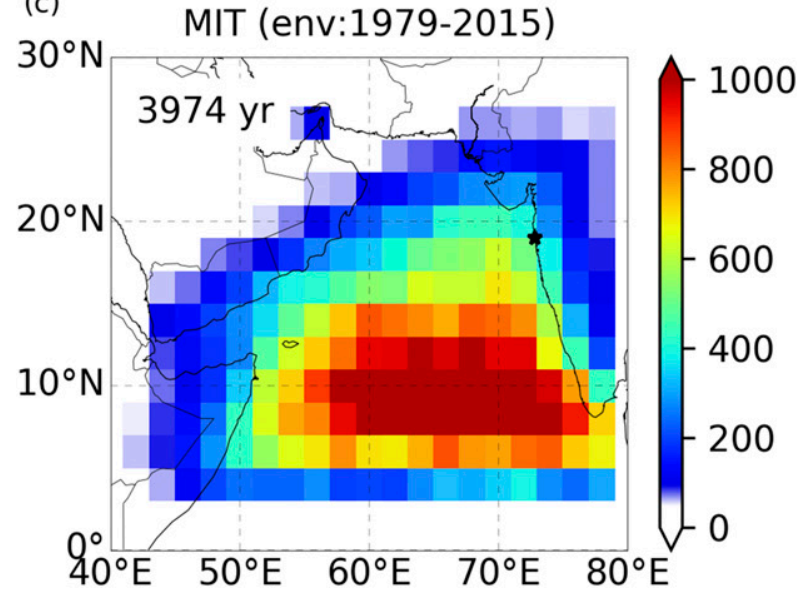

FIG. 6. ACE $\left(\mathrm{m}^{2} \mathrm{~s}^{-2} \mathrm{yr}^{-1}\right)$ from (a),(b) CHAZ and (c) the MIT model. ACE in (a) and (c) is computed by dividing the total ACE (sum of squared wind speed over all storms in the sample) by the data sample period while in (b) we divide by the adjusted period (a shorter number of years), to calibrate for the low-frequency bias in CHAZ as described in the text. The periods used are labeled on the upper-left corners of the plots.
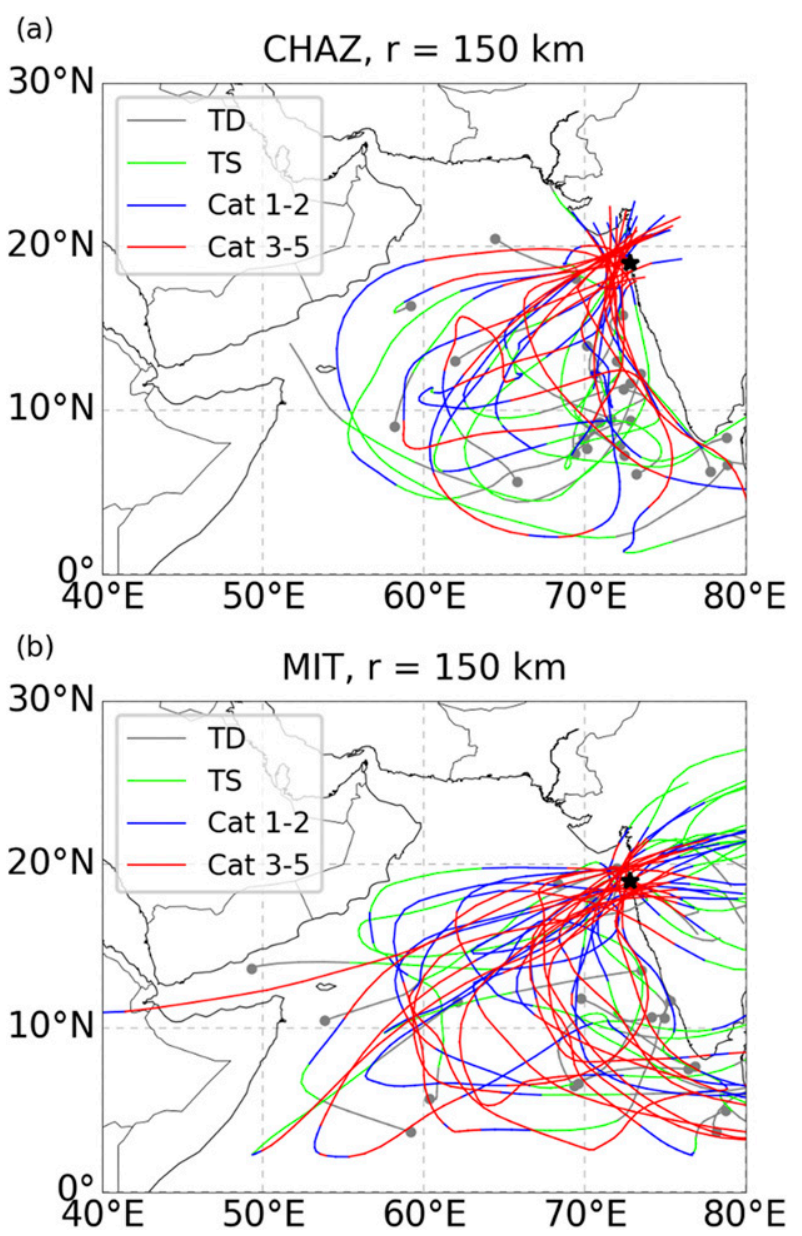

FIG. 7. Tracks of the 30 most intense storms to come within $150 \mathrm{~km}$ of Mumbai in (a) CHAZ and (b) the MIT model.

The shapes of the curves are not adjusted in either model. Thus any TC frequency biases in the observations will also be present in the return period curves to the extent that they influence the calibrations applied, but intensity biases will not affect the model results (unless they cause frequency biases, i.e., by causing storms exceeding $34 \mathrm{kt}$ to be classified as not exceeding that threshold). At the same time, frequency biases in the models will be corrected to the observations, while intensity biases will not be. Since the low biases in ACE present in the models are at least to some extent results of low frequency biases, these will be-to that extent-corrected.

For weaker wind speed thresholds, the estimated return periods in CHAZ, in the MIT model, and in observations are close to each other over most of the range shown. Larger differences in the return period curves between the MIT model and CHAZ remain at longer return periods. The differences between the two models for both sets of return period curves-for actual 
(a)

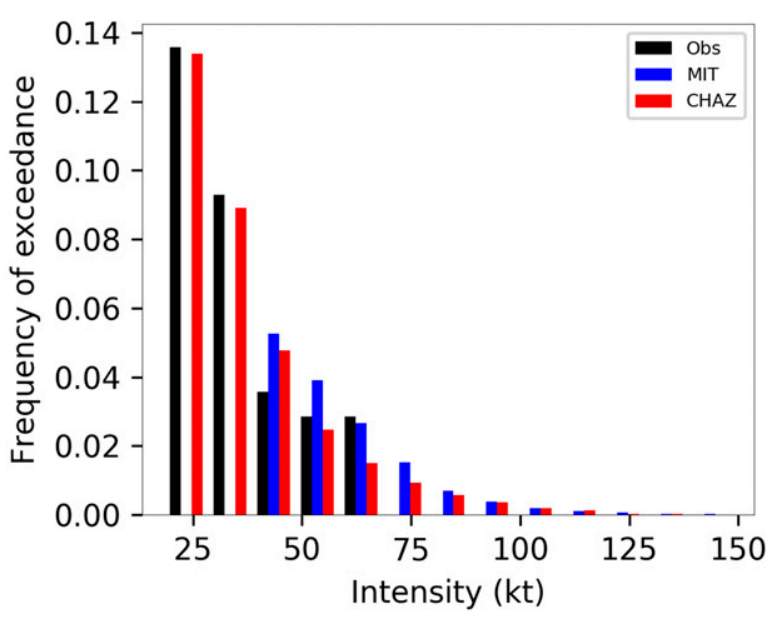

(b)

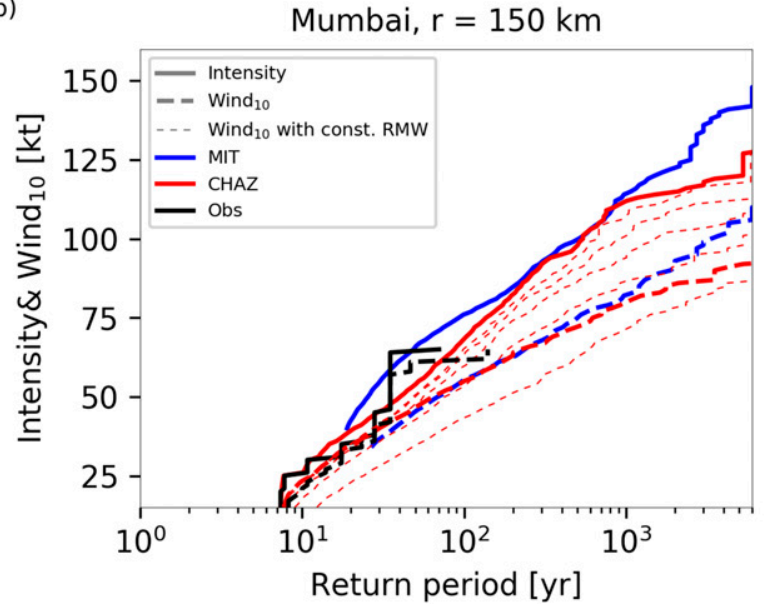

FIG. 8. (a) Annual frequency of exceedance for intensities of storms passing within $150 \mathrm{~km}$ of Mumbai from observations (black), CHAZ (red), and the MIT model (blue). (b) Return period (yr) of storm intensity within $150 \mathrm{~km}$ of Mumbai (solid lines) and actual wind speed experienced at Mumbai (dashed lines). The red thin dashed lines are the estimated return period curves of actual wind speed using constant radius of maximum wind (RMW) values varying from 30 to $110 \mathrm{~km}$ in $20-\mathrm{km}$ increments.

wind speed at Mumbai and for storm intensity within $150 \mathrm{~km}$ - are sensitive to the RMW. To examine the sensitivity of return period curves to RMW, we conducted experiments with $\mathrm{CHAZ}$ using constant RMW values ranging from 30 to $110 \mathrm{~km}$ with a $20-\mathrm{km}$ increment. The estimates of RMW from Knaff et al. (2015) are approximately within this range for most storms in our model.

As expected, the larger the RMW, the shorter the return period is at the same actual wind speed. The return period for a wind speed at Mumbai of $100 \mathrm{kt}$ is 3339 years in the MIT model; with the Knaff et al. (2015) relation for RMW, the return period for $100 \mathrm{kt}$ is estimated at 21000 years in CHAZ, but is not adequately resolved as there is only one event exceeding that threshold in our sample. For larger values of RMW, held constant for all storms, the return period in CHAZ decreases, since the storm center need not come as close to Mumbai in order to generate high winds there; the values are 5281, 1509, 918, and 812 years with RMW values of $50,70,90$, and $110 \mathrm{~km}$ respectively. For a storm with a maximum intensity of $100 \mathrm{kt}$ whose center passes within $150 \mathrm{~km}$ of Mumbai, the return periods are 541 years in CHAZ (using Knaff et al. 2015), and 509 years in the MIT model. For the lower threshold of $65 \mathrm{kt}$ (the minimum value for hurricane intensity on the SaffirSimpson scale), the return periods for wind at Mumbai are 236 years in the MIT model and 224 years in CHAZ, while those for a $65-\mathrm{kt}$ storm passing within $150 \mathrm{~km}$ of Mumbai are 49 and 97 years in the MIT model and CHAZ, respectively [using the Knaff et al. (2015) relation for RMW in the latter].

\section{Discussion}

This study is limited in a number of ways. In the first place, we measure tropical cyclone hazard only in terms of wind speed. While wind could potentially do great damage in Mumbai, the most severe outcomes would be likely to result from flooding. Heavy precipitation from a slow-moving TC could certainly cause a major flood, comparable to the one in 2005 (or perhaps even greater, as the very heavy rains in that event were limited to only part of the city). Storm surge, however, may pose the greatest threat.

We have not evaluated storm surge risk here, but are investigating this in ongoing research. This work is hindered by the fact that, as far as we can tell, no digital elevation model is publicly available for Mumbai with sufficient resolution and accuracy to simulate inundation in the city reliably. At this point, we can simply hypothesize-with some support from our preliminary calculations (not shown) - that a TC at the higher end of the intensity spectrum shown above would have the potential to create a surge of several meters. This could cause extensive inundation, particularly if the peak surge were to occur close to the time of high tide.

The second major limitation of our study is that we do not consider the effects of anthropogenic climate change. We consider the entire historical period as a single entity, without examining trends, and our hazard model simulations are conditioned on the recent historical climate. Recent studies with relatively highresolution global dynamical models have concluded that Arabian Sea TC activity is likely to increase in the future as the climate warms (Murakami et al. 2013) and that, in fact, the observed recent increase in occurrence of high-intensity storms is already attributable to 
anthropogenic warming (Murakami et al. 2017). Increases in Arabian Sea TC activity are expected in a warming climate as a consequence of increases in Arabian Sea surface and upper ocean temperatures, not only in an absolute sense but also relative to those in the Bay of Bengal. The relative Arabian Sea warming is a robust signal in simulations of greenhouse warming, meaning that it is consistent across many models (e.g., Zheng et al. 2013; Liu et al. 2015; Yao et al. 2016). This does not mean that it is necessarily correct, and it has been argued that the relative Arabian Sea warming is an artifact (Li et al. 2016) though that conclusion has again been questioned on methodological grounds (Wang et al. 2017). It may also be the case that trends in the historical record are challenged by changes in observing practices (Landsea et al. 2006; Hoarau et al. 2012), for example, because of changing implementations of the Dvorak technique for TC intensity estimation (Velden et al. 2006). Notwithstanding these debates, we view it as still quite relevant at this time to consider the implications for tropical cyclones of the relative Arabian Sea warming projected by the models.

In a future study we will apply our hazard models to address the anthropogenic influence by using those models to produced downscaled TC tracks from simulations of future climate scenarios from the CMIP ensembles. Since TC behavior is conditioned on largescale environmental data in both models used here, both are suited to consider how changes in the largescale climate will influence TC activity, and the MIT model has already been used for studies of this kind in other regions (e.g., Lin et al. 2010, 2012). At present, we simply speculate that the results presented here underestimate the hazard that Mumbai faces-not only in the future, but even in the present, given that some warming has already been realized and appears to have increased the hazard compared to just a couple of decades ago (Murakami et al. 2017).

\section{Conclusions}

In this study, we have assessed Mumbai's tropical cyclone (TC) hazard in the recent historical climate. Our interest is in the probability that the city could be struck by a high-intensity TC, one potentially powerful enough to generate a large storm surge in addition to direct wind damage, although surge is not explicitly considered here.

We first addressed previously published accounts of a major TC landfall in Bombay (the prior name of Mumbai) on 6 June 1882. Primary sources from the time show no indication that any such cyclone occurred, and we draw the conclusion that none did occur. We do not know the original source of the apparently fictional accounts indicating that one did. Our conclusion here was published earlier by Ghosh (2017), but we view it as important to document it in the peer-reviewed scientific literature as well.

We then presented statistics of TC tracks from historical best track data, from both the satellite era and a longer historical period beginning in the nineteenth century, as well as from two hazard models which generate synthetic tracks consistent with the historical record. The hazard models generate synthetic records much longer than the historical one, allowing hazard at long return periods to be assessed. The obvious limitation is that the models are not reality, and could have systematic errors. The difference between the two different models gives at least a very crude and preliminary notion of what the scientific uncertainty may be at these longer return periods; while multimodel ensemble spread is not true uncertainty and an ensemble of two models is a very small one in any case, it is nonetheless preferable to a single model.

The results indicate that, despite the absence of major TC strikes in Mumbai's recent history, there is a finite probability that one could occur. The return period of a storm with maximum sustained winds exceeding $100 \mathrm{kt}$ (category 3 or higher on the Saffir-Simpson hurricane wind scale used in the United States; the threshold for an extremely severe cyclonic storm on the scale used by the India Meteorological Department is $90 \mathrm{kt}$ ) passing within $150 \mathrm{~km}$ of Mumbai is on the order of 500 years according to both models used here. The return period for winds of that intensity at Mumbai itself is in the range of $\sim 3000$ years (MIT model) to greater than 10000 years (CHAZ). Return periods for $65-\mathrm{kt}$ winds are $\sim 200$ years (in both models) for actual wind at Mumbai, and 50-90 years (in both models, consistent with observations which marginally resolve these periods) for intensity within $150 \mathrm{~km}$. While storm surge hazard is a topic for future work and not assessed here, and the surge depends not only on maximum wind speed but also storm track, translation speed, size, and other parameters, our result nonetheless suggest that a storm of sufficient intensity to generate a large surge along Mumbai's coast, and significant inundation in the city, particularly if the peak surge were to occur close to high tide, is possible.

The historical tracks show a number of major cyclone landfalls over the last few decades in Gujarat, to Mumbai's north along the Arabian Sea coast. These storms reach the coast traveling northward from farther south, and spare Mumbai by not turning right. To what extent this is a fundamental feature of the region's TC climatology, as opposed to an accident of 
historical sampling in a region where TCs are rare overall, is an interesting subject for future study. Here, in addition to pointing out that the hazard models do produce major TC landfalls near Mumbai, we also simply note that the absence of a given track type in relatively short historical records is no guarantee that a track of this type cannot occur in the future. This was demonstrated vividly, for example, by the recent leftturning track of Hurricane Sandy (2012) in the North Atlantic, resulting in the subsequent unprecedented near-perpendicular landfall in New Jersey (Hall and Sobel 2013), and major impacts on New York City and the surrounding region (e.g., Sobel 2014).

Our study is only a first step in assessing Mumbai's risk. Besides omitting any explicit consideration of either storm surge or precipitation, we also do not address the role of anthropogenic climate change, which other recent studies indicate is increasing the proclivity of the Arabian Sea toward major cyclone activity, suggesting that our results underestimate the present and future hazard. Sea level rise, of course, is also increasing the flood hazard from storm surge from any given level of TC hazard (e.g., Woodruff et al. 2013; Walsh et al. 2016). Work in progress will address some of these issues and will be reported in due course. Analysis of the future economic risk to coastal cities worldwide from sea level rise has ranked Mumbai among those cities most at risk globally (Ranger et al. 2011; Hallegatte et al. 2013 see also Dhiman et al. 2019); to our knowledge these analyses have not explicitly considered the storm surge hazard from a potential major tropical cyclone, having been based on historical tide gauge data, which include no such event. While the probability of a major TC landfall in Mumbai is small, our results suggest it is large enough that, particularly given the city's coastal exposure, low elevation, large population, and economic and cultural importance, this problem bears further consideration, both from scientific and operational points of view. A TC landfall in Mumbai with widespread inundation caused by storm surge would likely pose major difficulties both for shortterm emergency management and longer-term recovery, but well-informed preparations could reduce these. Additional studies of the risks to Mumbai's population, economy, and infrastructure from a potential major TC landfall would be justified, as would planning to reduce those risks.

Acknowledgments. AHS, CYL, SJC, and KTM acknowledge support from the Columbia University President's Global Innovation Fund and the Columbia Initiative on Extreme Weather and Climate. We thank participants in a workshop held at the Columbia Global Center in Mumbai, India, in January 2017 for broad, stimulating discussions, and the Global Center for their help in organizing it and supporting our project. We also thank Drs. Matthieu Lengaigne and I. Suresh (National Institute of Oceanography, Goa, India) for insights on Indian Ocean climate change; Profs. Gyan Prakash (Princeton University) and Sunil Amrith (Harvard University) for correspondence and advice on the (fictional) Bombay cyclone of 1882; and Amitav Ghosh for the discussions, which initially inspired this work, as described in his book The Great Derangement. We thank Dr. D. Chavas (Purdue University) for providing the parametric wind model, CLE15.

\section{REFERENCES}

Camargo, S. J., M. K. Tippett, A. H. Sobel, G. A. Vecchi, and M. Zhao, 2014: Testing the performance of tropical cyclone genesis indices in future climates using the HIRAM model. J. Climate, 27, 9171-9196, https://doi.org/10.1175/JCLI-D-1300505.1.

Chavas, D. R., N. Lin, and K. Emanuel, 2015: A model for the complete radial structure of the tropical cyclone wind field. Part I: Comparison with observed structure. J. Atmos. Sci., 72, 3647-3662, https://doi.org/10.1175/JAS-D-15-0014.1.

Chester, B., 1964: Earthquakes, tidal waves cause historic disasters. The Evening Independent, 31 March, https://news.google.com/ newspapers? nid $=950 \& \mathrm{dat}=19640331 \& \mathrm{id}=\mathrm{xRMwAAAAIBAJ} \&$ sjid $=3$ VYDAAAAIBAJ\&pg $=7088,5284525 \& \mathrm{hl}=$ en .

Daloz, A. S., and Coauthors, 2015: Cluster analysis of downscaled and explicitly simulated North Atlantic tropical cyclones tracks. J. Climate, 28, 1333-1361, https://doi.org/10.1175/ JCLI-D-13-00646.1.

Dee, D. P., and Coauthors, 2011: The ERA-Interim reanalysis: Configuration and performance of the data assimilation system. Quart. J. Roy. Meteor. Soc., 137, 553-597, https:// doi.org/10.1002/qj.828.

Dhiman, R., R. VishnuRadhan, T. I. Eldho, and A. Inamdar, 2019: Flood risk and adaptation in Indian coastal cities: Recent scenarios. Appl. Water Sci., 9 (5), https://doi.org/10.1007/s13201018-0881-9.

Dube, S. K., P. C. Sinha, A. D. Rao, and G. S. Rao, 1985: Numerical modelling of storm surges in the Arabian Sea. Appl. Math. Model., 9, 289-294, https://doi.org/10.1016/ 0307-904X(85)90067-8.

Eliot, J., 1893: Cyclone Memoirs, No. 1-5. Office of the Superintendent of Government Printing, India, $252 \mathrm{pp}$.

Emanuel, K. A., 2005: Divine Wind: The History and Science of Hurricanes. 1st ed. Oxford University Press, 296 pp.

- 2 2006: Climate and tropical cyclone activity: A new model downscaling approach. J. Climate, 19, 4797-4802, https:// doi.org/10.1175/JCLI3908.1.

—, R. Sundararajan, and J. Williams, 2008: Hurricanes and global warming: Results from downscaling IPCC AR4 simulations. Bull. Amer. Meteor. Soc., 89, 347-367, https://doi.org/ 10.1175/BAMS-89-3-347.

Evan, A. T., and S. J. Camargo, 2011: A climatology of Arabian Sea cyclonic storms. J. Climate, 24, 140-158, https://doi.org/ 10.1175/2010JCLI3611.1.

Ghosh, A., 2017: The Great Derangement: Climate Change and the Unthinkable. 1st ed. University of Chicago Press, 204 pp. 
Hall, M., 1947: Hurricane second only to tornado in wind violence. The Nashua Telegraph, 17 September, https://news.google.com/ newspapers? $\mathrm{nid}=2209 \& \mathrm{dat}=19470917 \& \mathrm{id}=\mathrm{yrMrAAAAIBAJ} \& \mathrm{sjid}=$ 3f4FAAAAIBAJ\&pg $=2937,1950082 \& \mathrm{hl}=\mathrm{en}$.

Hall, T. M., and A. H. Sobel, 2013: On the impact angle of Hurricane Sandy's New Jersey landfall. Geophys. Res. Lett., 40, 2312-2315, https://doi.org/10.1002/grl.50395.

Hallegatte, S., C. Green, R. J. Nicholls, and J. Corfee-Morlot, 2013: Future flood losses in major coastal cities. Nat. Climate Change, 3, 802-806, https://doi.org/10.1038/nclimate1979.

Hoarau, K., J. Bernard, and L. Chalonge, 2012: Intense tropical cyclone activities in the northern Indian Ocean. Int. J. Climatol., 32, 1935-1945, https://doi.org/10.1002/joc.2406.

Jenamani, K. R., S. C. Bhan, and S. R. Kalsi, 2006: Observational/ forecasting aspects of the meteorological event that caused a record highest rainfall in Mumbai. Curr. Sci., 90, 1344-1362.

Kalnay, E., and Coauthors, 1996: The NCEP/NCAR 40-Year Reanalysis Project. Bull. Amer. Meteor. Soc., 77, 437-471, https:// doi.org/10.1175/1520-0477(1996)077<0437:TNYRP>2.0.CO;2.

Knaff, J. A., S. P. Longmore, R. T. DeMaria, and D. A. Molenar, 2015: Improved tropical-cyclone flight-level wind estimates using routine infrared satellite reconnaissance. J. Appl. Meteor. Climatol., 54, 463-478, https://doi.org/10.1175/JAMC-D-14-0112.1.

Knapp, K. R., M. C. Kruk, D. H. Levinson, H. J. Diamond, and C. J. Neumann, 2010: The International Best Track Archive for Climate Stewardship (IBTrACS): Unifying tropical cyclone data. Bull. Amer. Meteor. Soc., 91, 363-376, https://doi.org/ 10.1175/2009BAMS2755.1.

Landsea, C. W., B. Harper, K. Hoarau, and J. A. Knaff, 2006: Can we detect trends in extreme tropical cyclones? Science, $\mathbf{3 1 3}$, 452-454, https://doi.org/10.1126/science.1128448.

Lee, C.-Y., M. K. Tippett, S. J. Camargo, and A. H. Sobel, 2015: Probabilistic prediction of tropical cyclone intensity from a multiple-linear regression model. Mon. Wea. Rev., 143, 933954, https://doi.org/10.1175/MWR-D-14-00171.1.

,,-- A. H. Sobel, and S. J. Camargo, 2016: Autoregressive modeling for tropical cyclone intensity climatology. J. Climate, 29, 7815-7830, https://doi.org/10.1175/JCLI-D-15-0909.1.

,,-- , and,- 2018 : An environmentally forced tropical cyclone hazard model. J. Adv. Model. Earth Syst., 10, 223-241, https://doi.org/10.1002/2017MS001186.

Li, G., S.-P. Xie, and Y. Du, 2016: A robust but spurious pattern of climate change in model projections over the tropical Indian Ocean. J. Climate, 29, 5589-5608, https://doi.org/10.1175/ JCLI-D-15-0565.1.

Lin, N., K. A. Emanuel, J. A. Smith, and E. Vanmarcke, 2010: Risk assessment of hurricane storm surge for New York City. J. Geophys. Res., 115, D18121, https://doi.org/10.1029/2009JD013630.

M. Oppenheimer, and E. Vanmarcke, 2012: Physically based assessment of hurricane surge threat under climate change. Nat. Climate Change, 2, 462-467, https://doi.org/ 10.1038/nclimate1389.

Liu, W., J. Lu, and S.-P. Xie, 2015: Understanding the Indian Ocean response to double $\mathrm{CO}_{2}$ forcing in a coupled model. Ocean Dyn., 65, 1037-1046, https://doi.org/10.1007/s10236-015-0854-6.
Longshore, D., 2008: Encyclopedia of Hurricanes, Typhoons, and Cyclones. 1st ed. Checkmark Books, 468 pp.

Mohapatra, M., B. K. Bandyopadhyay, and A. Tyagi, 2012: Best track parameters of tropical cyclones over the North Indian Ocean: A review. Nat. Hazards, 63, 1285-1317, https://doi.org/ 10.1007/s11069-011-9935-0.

Murakami, H., M. Sugi, and A. Kitoh, 2013: Future changes in tropical cyclone activity in the North Indian Ocean projected by high-resolution MRI-AGCMs. Climate Dyn., 40, 19491968, https://doi.org/10.1007/s00382-012-1407-z.

_ - G. A. Vecchi, and S. Underwood, 2017: Increasing frequency of extremely severe cyclonic storms over the Arabian Sea. Nat. Climate Change, 7, 885-889, https://doi.org/10.1038/s41558017-0008-6.

Ranger, N., and Coauthors, 2011: An assessment of the potential impact of climate change on flood risk in Mumbai. Climatic Change, 104, 139-167, https://doi.org/10.1007/s10584010-9979-2.

Sobel, A. H., 2014: Storm Surge: Hurricane Sandy, Our Changing Climate, and Extreme Weather of the Past and Future. 1st ed. Harper-Collins, 336 pp.

Tippett, M. K., S. J. Camargo, and A. H. Sobel, 2011: A Poisson regression index for tropical cyclone genesis and the role of large-scale vorticity in genesis. J. Climate, 24, 2335-2357, https://doi.org/10.1175/2010JCLI3811.1.

Velden, C., and Coauthors, 2006: The Dvorak tropical cyclone intensity estimation technique: A satellite-based method that has endured for over 30 years. Bull. Amer. Meteor. Soc., 87, 1195-1210, https://doi.org/10.1175/BAMS-87-91195.

Walsh, K., and Coauthors, 2016: Tropical cyclones and climate change. Wiley Interdiscip. Rev.: Climate Change, 7, 65-89, https://doi.org/10.1002/wcc.371.

Wang, G., W. Cai, and A. Santoso, 2017: Assessing the impact of model biases on the projected increase in frequency of extreme positive Indian Ocean dipole events. J. Climate, 30, 2757-2767, https://doi.org/10.1175/JCLI-D-16-0509.1.

Warrier, S. G., 2017: Mumbai floods: Why India's cities are struggling with extreme rainfall. The Hindustan Times, 29 August, https://www.hindustantimes.com/india-news/mumbai-floodswhy-india-s-cities-are-struggling-with-extreme-rainfall/storywsWPNy2MXh4b9JYTqtA0QJ.html.

Woodruff, J. D., J. L. Irish, and S. J. Camargo, 2013: Coastal flooding by tropical cyclones and sea-level rise. Nature, 504, 44-52, https://doi.org/10.1038/nature12855.

Yao, S.-L., G. Huang, R.-G. Wu, X. Qu, and D. Chen, 2016: Inhomogeneous warming of the tropical Indian Ocean in the CMIP5 model simulations during 1900-2005 and associated mechanisms. Climate Dyn., 46, 619-636, https://doi.org/10.1007/ s00382-015-2602-5.

Zheng, X.-T., S.-P. Xie, Y. Du, L. Liu, G. Huang, and Q. Liu, 2013: Indian Ocean dipole response to global warming in the CMIP5 multimodel ensemble. J. Climate, 26, 6067-6080, https://doi.org/10.1175/JCLI-D-12-00638.1. 